\title{
O Programa de Saúde da Família
} e a Puericultura*

\author{
Family Health Care Program \\ and child health care
}

Luiz Antonio Del Ciampo 1

Rubens Garcia Ricco ${ }^{1}$

Julio César Daneluzzi 1

Ieda Regina Lopes Del Ciampo 2

Ivan Savioli Ferraz 1

Carlos Alberto Nogueira de Almeida 2

\footnotetext{
* Trabalho desenvolvido com o apoio da Faepa Fundação de Amparo ao Ensino, Pesquisa e Assistência do Hospital das Clínicas da Faculdade de Medicina de Ribeirão Preto da Universidade de São Paulo.

1 Departamento de Puericultura e Pediatria, Faculdade de Medicina de Ribeirão Preto, Universidade de São Paulo. Av. dos Bandeirantes 3.900 Monte Alegre, 14049-900 Ribeirão Preto SP.

delciamp@fmrp.usp.br 2 Curso de Medicina, Universidade de Ribeirão Preto.
}

\begin{abstract}
This paper suggests a proposal of Child Health Care, to children and adolescents, to be developed in the Family Health Care Programs. Key words Primary care, Child health, Family health, Family practice, Primary child care
\end{abstract}

Resumo O trabalho apresenta uma proposta de atendimento em Puericultura, para crianças e adolescentes, que pode ser desenvolvida no contexto das atividades dos Programas de Medicina de Família e Comunidade.

Palavras-chave Atenção primária em saúde, Puericultura, Medicina de família e comunidade, Programa de Saúde da Família, Atenção primária em pediatria 


\section{Introdução}

Os serviços de atendimento à saúde são estruturados pela sociedade de modo a atender dois objetivos principais:

1) a otimização da saúde da população por intermédio do conhecimento atualizado das causas e manejo das doenças, visando maximizar o bem-estar físico, emocional e social;

2) a redução das diferenças de oportunidades entre os distintos grupos populacionais, no que diz respeito ao acesso aos serviços de saúdel.

Dentre os diferentes modelos de serviços de saúde, pode-se destacar aqueles que se incumbem de oferecer a chamada Atenção Básica à Saúde, cujo trabalho utiliza, fundamentalmente, profissionais com grande base de conhecimento, atuando com uma visão interdisciplinar, com o objetivo de aumentar o índice de resolução dos problemas, sem causar elevação dos custos². A atenção primária à saúde ocupa, desde a 30a Reunião Anual da Assembléia Mundial da Saúde, realizada em 1977, lugar de destaque entre as ações de saúde empreendidas nas últimas três décadas em todo o mundo. Em 1978, após a Conferência de Alma-Ata, ela foi reconhecida como uma ação integral e permanente que deve compor os sistemas de saúde bem estruturados e comprometidos com a qualidade de vida dos cidadãos, tratando simultaneamente o indivíduo e a sua comunidade.

A Atenção Básica é desenvolvida por meio de um conjunto de ações práticas que requerem, para sua implementação, grande pluralidade de atitudes, habilidades e conhecimentos técnicos e científicos de relativa baixa complexidade. Pode ser entendida como o nível de entrada no sistema de saúde, fornecendo atenção sobre a pessoa para todas as condições, além de coordenar e integrar a atenção obtida em outro lugar ou por terceiros. Representa a base do trabalho de todos os outros níveis do sistema de saúde e atua de modo a oferecer ações de promoção de saúde, prevenção de doenças, tratamento e reabilitação. A Atenção Básica enfoca os problemas de saúde mais prevalentes de cada grupo social. Suas ações visam a modificar as condições de vida da comunidade, em função do controle de fatores sociais e ambientais, além de hábitos e estilos de vida, com o propósito de estimular atitudes saudáveis e eliminar riscos $1,3,4$.

\section{A proposta de atuação}

Apoiado nesses preceitos e procurando refletir experiências realizadas em outros países, é implantado no Brasil, em 1994, o Programa de Saúde da Família (PSF), com a proposta de modificar e expandir o acesso da população aos serviços de saúde, tornando-se a porta de entrada do sistema vigente até então. Segundo o Ministério da Saúde 5 , trata-se de uma estratégia que possibilita a integração e promove a organização das atividades em um território definido, com o propósito de propiciar o enfrentamento e a resolução dos problemas identificados. Atuando sob a luz dos princípios de integralidade, hierarquização, territorialização e trabalho em equipe multiprofissional, tem como uma de suas principais metas a redução das desigualdades regionais por meio de intervenções personalizadas e individualizadas 2 .

Como estratégia diretamente relacionada à atenção primária, o PSF deve procurar compreender a saúde das pessoas no contexto dos seus diversos determinantes, quer seja no ambiente físico da comunidade, quer seja nas relações sociais, alcançando muito além do simples enfoque sobre a enfermidade dos cidadãos. A família, além do indivíduo, passa a ser objeto de atenção no ambiente onde vive, ampliandose a sua compreensão diante do processo saúde/doença. Em 2004, o País contava com 17.608 equipes, que atuavam em 49.276 municípios e cobriam cerca de 57 milhões de habitantes. Este número vem crescendo continuamente6.

Estimativas feitas a partir do censo de 2000 apontam que a população brasileira conta, atualmente, com mais de 178 milhões de habitantes. Destes, cerca de 40\% (mais de $70 \mathrm{mi}-$ lhões) encontram-se na faixa etária que vai do nascimento aos 19 anos, sendo 33,6 milhões de crianças até 10 anos de idade e 36,4 milhões de adolescentes7.

Os programas estruturados para oferecer Atenção Básica à saúde da criança têm como metas principais promoção da saúde, prevenção de doenças, tratamento e reabilitação. Necessitam da efetiva participação do indivíduo e da sociedade, pressupondo a integração de diversas classes profissionais que atuam em equipe, devidamente calcados nos saberes interdisciplinares e apoiados pelos diferentes níveis de referência do sistema de saúde. Promover e recuperar a saúde e o bem-estar da criança têm sido, há muito tempo, prioridade dentro da assistência à saúde infantil, a fim de garantir o 
crescimento e o desenvolvimento adequados dos menores nos aspectos físico, emocional e social. Desta forma asseguramos o pleno desenvolvimento do potencial genético da criança, que levará a um adulto mais saudável, capaz e feliz possível, bem como procuramos reduzir as elevadas taxas de morbidade e mortalidade ainda verificadas em diversas populações $8,9,10$.

A puericultura, área da pediatria voltada principalmente para os aspectos de prevenção e de promoção da saúde, atua no sentido de manter a criança saudável para garantir seu pleno desenvolvimento, de modo que atinja a vida adulta sem influências desfavoráveis e problemas trazidos da infância. Suas ações priorizam a saúde em vez da doença. Seus objetivos básicos contemplam a promoção da saúde infantil, prevenção de doenças e educação da criança e de seus familiares, por meio de orientações antecipatórias aos riscos de agravos à saúde, podendo oferecer medidas preventivas mais eficazes. Para ser desenvolvida em sua plenitude, deve conhecer e compreender a criança em seu ambiente familiar e social, além de suas relações e interação com o contexto socioeconômico, histórico, político e cultural em que está inserida. Isto se torna fundamental pois as ações médicas, além de serem dirigidas à criança, refletem-se sobre o seu meio social, a começar pela família. Sem o envolvimento desta, as ações que visem às crianças não terão sucesso ${ }^{11}$.

O profissional médico que pratica a Puericultura, por meio de revisões periódicas, deve desempenhar seu trabalho com ações não apenas clínicas, mas com uma concepção epidemiológica e social, relacionando-as intimamente com o complexo saúde-indivíduo-família-comunidade 3 . O puericultor, como é também chamado este médico, deve oferecer apoio constante à família, auxiliando na minimização dos efeitos sociais e emocionais das doenças sobre a criança e seus familiares ${ }^{12}$.

Dentre os vários papéis desempenhados pelo puericultor destacam-se o de orientador e educador para a saúde, cujo trabalho se direciona à mãe e à família. Esta, por ser o núcleo principal dos fatores ambientais e psicossociais, e aquela, tendo fortalecido o vínculo com o filho e mantendo sua auto-estima elevada, podem assegurar os melhores cuidados à criança. Citando o inesquecível professor Eduardo Marcondes, podemos afirmar que o puericultor não atende crianças e sim, famílias ${ }^{13}$.

Diante das considerações apresentadas e da experiência profissional dos autores, adquirida em várias décadas de atuação na área de atendimento de Puericultura e atenção primária em Pediatria, este texto pretende divulgar a proposta de um programa de atendimento em Puericultura que possa ser incorporado às atividades do Programa de Saúde da Família.

Este Programa de Puericultura (PPUE) deve se estender a toda a população na faixa etária que vai do nascimento aos 20 anos incompletos, com seguimento longitudinal e distinto entre as diferentes idades, e ser realizado por meio de atendimento ambulatorial individualizado, visitas domiciliares e participação em grupos de educação e socialização ${ }^{14}$. Independentemente da faixa etária atendida, seus objetivos gerais são:

a) vigiar o crescimento físico e o desenvolvimento neuropsicomotor e intelectual;

b) ampliar a cobertura vacinal;

c) promover a educação alimentar e nutricional;

d) promover a segurança e a prevenção de acidentes;

e) promover a prevenção de lesões intencionais, principalmente no ambiente doméstico;

f) estimular a promoção da saúde e a prevenção das doenças mais comuns na comunidade; g) promover a higiene física e mental e a prática de atividades de lazer adequadas às faixas etárias;

h) propiciar a socialização, estimulação cultural e adaptação da criança e do adolescente em seu meio social.

De acordo com as diferentes faixas etárias dos pacientes, o PPUE observa algumas particularidades:

a) O recém-nascido $(\mathrm{RN})$ : suas principais características são a completa dependência do adulto para sobrevivência, grande imaturidade e incapacidade de controlar impulsos e emoções. Trata-se de uma criança que apresenta maiores riscos e necessita de cuidados mais intensos. Portanto, durante a primeira semana de vida, após a alta hospitalar, deverá receber visita domiciliar de uma enfermeira, auxiliar de enfermagem ou agente comunitário de saúde. Os objetivos desta visita são proporcionar maior contato entre o binômio mãe-filho e, por parte da equipe de Saúde da Família, identificar dúvidas e dificuldades da puérpera em desempenhar o papel de mãe, oferecer orientações sobre os cuidados básicos ao recém-nascido e avaliar a adaptação da criança ao meio extra-uterino. É uma excelente oportunidade para fortalecer a implantação e estimular a prática do aleitamento materno. Ao término dessa visita, já 
será marcada a primeira consulta médica do RN para sua matrícula no programa;

b) O lactente: caracteriza-se por ser uma criança que se encontra em um período de rápido crescimento pôndero-estatural e desenvolvimento neuromotor, que evolui rapidamente de uma condição de vida dependente para uma vida de relacionamento com os pais e com o ambiente familiar, ganhando autonomia progressivamente. A criança adquire maior movimentação voluntária, amplia seu espaço social e é muito estimulada pelo ambiente. Nesta ocasião ocorrem ainda o início da construção da inteligência e a fase oral do desenvolvimento da personalidade. As crianças nesta faixa etária, que se estende dos 28 dias aos dois anos de vida, serão acompanhadas por consultas médicas mensais, durante o primeiro semestre de vida, bimestrais, no segundo semestre, e trimestrais, entre 12 e 24 meses de idade;

c) O pré-escolar: período que se estende dos dois aos sete anos de idade, caracterizado por desaceleração do crescimento e menores necessidades nutricionais do que na fase anterior. Com a especialização do desenvolvimento neuromotor, a criança vai adquirindo autonomia, ampliando o seu ambiente social e diminuindo a dependência dos adultos, que se torna mais emocional e intelectual do que física. Sua evolução sócio-adaptativa e cognitiva permite o início do processo de aprendizagem formal, embora ainda tenha pequena capacidade de prever riscos e de reconhecer o perigo. O objetivo é obter um candidato fisicamente forte, mentalmente capaz e socialmente ajustado para entrar na escola. As crianças serão avaliadas em consultas médicas semestrais entre dois e sete anos;

d) O escolar: caracteriza-se por ser um período de crescimento estável, quando o sistema nervoso central está se completando e pronto para receber alfabetização e realizar operações concretas. Nesta fase, a criança sofre muitas influências externas e é insuficiente e inadequadamente vigiada pelos adultos. O programa indica consultas médicas semestrais, entre sete e 10 anos de idade;

e) A adolescência: inicia-se aos 10 anos, caracterizando-se por significativas e intensas mudanças físicas e emocionais, que visam a preparar o indivíduo para a vida adulta, definindo sua identidade e integração social. Neste período, ocorre a maturidade física e reprodutiva, identidade sexual e psíquica e independência emocional. $\mathrm{O}$ adolescente necessita de auto-afirmação, pois ainda é inexperiente e apresenta espírito desafiador e aventureiro. A partir dos 10 anos, as consultas são semestrais até os 20 anos de idade. Atenção especial deverá ser dada para o estadiamento puberal que ocorre durante este período, avaliando-se a maturidade sexual.

\section{Considerações finais}

Finalmente, a propósito das considerações discutidas acima, podemos recordar o verso do poeta inglês W. Wordsworth (1770-1850) “a criança é o pai do homem”, que consegue aquilatar a importância de um programa de Puericultura eficiente e contínuo, desde o nascimento (ou até mesmo antes dele), na projeção do adulto mais saudável e feliz, pleno de suas potencialidades e cidadania. De tal forma, estamos tão convictos de sua importância que não hesitamos afirmar que a Atenção Integral à Saúde da Criança e do Adolescente somente se plenifica ética e tecnicamente quando inclui, nos papéis de todos os membro da equipe que dela participam, a doutrina e a prática da Puericultura.

\section{Colaboradores}

Os autores participaram igualmente de todas as etapas da elaboração do artigo. 


\section{Referências}

1. Starfield B. Atenção Primária: equilíbrio entre necessidades de saúde, serviços e tecnologia. Brasília: Unesco; 2002.

2. Alves CRL, Viana MRA. Saúde da família: cuidando de crianças e adolescentes. Belo Horizonte: Editora Coopmed; 2003.

3. Dominguez BNR. O Programa de Saúde da Família: como fazer. 1a ed. São Paulo: CGE Computação Gráfica/Editora Ltda; 1998.

4. Martin Zurro A, Cano Pérez JF. Atención primária. Conceptos, organización y practica clínica. 4a ed. Madrid: Editora Hartcourt; 1999.

5. Ministério da Saúde. Saúde da Família: uma estratégia para a reorientação do modelo assistencial. Brasília: MS; 1998.

6. Brasil. Ministério da Saúde (MS) [acessado agosto 2005]. Atenção básica e saúde da família. Disponível em: http://www.dtr2001.saude.gov.br/psf//progra$\mathrm{ma} /$ index.asp.

7. Instituto Brasileiro de Geografia e Estatística (IBGE) [acessado agosto 2005]. Censos demográficos. Disponível em: http://www.ibge.gov.br/.
8. Crespin J. Puericultura. Ciência, arte e amor. São Paulo: Fundo Editorial BYK; 1992.

9. Del Ciampo LA, Ricco RG, Rosa F. Puericultura: uma prioridade a ser resgatada. Pediatria 1994; 16(4):15861.

10. Ricco RG, Del Ciampo LA, Almeida CAN. Puericultura: princípios e práticas. Atenção Integral à Saúde da Criança. 1a ed. São Paulo: Editora Atheneu; 2001.

11. Ricco RG, Almeida CAN, Del Ciampo LA. Puericultura: temas de pediatria 80. São Paulo: Nestlé; 2005.

12. Sociedade Brasileira de Pediatria (SBP). Puericultura ambulatorial. [Documento Científico]. Porto Alegre; [Fevereiro] 2004.

13. Issler H, Leone C, Marcondes E. Pediatria na atenção primária. 1ạ ed. São Paulo: Editora Sarvier; 1999.

14. Daneluzzi JC. Programas de Puericultura: uma experiência bem-sucedida. In: Ricco RG, Del Ciampo LA, Almeida CA. Puericultura: princípios e prática. Atenção integral à saúde da criança. 1a ed. São Paulo: Editora Atheneu; 2001. p. 5-8.

Artigo apresentado em 18/10/2005

Aprovado em 25/10/2005

Versão final apresentada em 30/11/2005 